\title{
Development and validation of a nomogram for predicting overall survival in papillary renal cell carcinoma: a retrospective cohort study
}

Jiawu Wang ( $\nabla$ wangjiawu19850806@126.com )

the Second Affiliated Hospital of Chongqing Medical University

Chengyao Zhang

Chongqing University Cancer Hospital \& Chongqing Cancer Institute \& Chongqing Cancer Hospital

Yanjun Lin

the Second Affiliated Hospital of Chongqing Medical University

Qing Jiang

the Second Affiliated Hospital of Chongqing Medical University

Research article

Keywords: nomogram, papillary renal cell carcinoma, SEER, prognosis, validation

Posted Date: September 17th, 2020

DOI: https://doi.org/10.21203/rs.3.rs-69349/v1

License: (c) (i) This work is licensed under a Creative Commons Attribution 4.0 International License.

Read Full License 


\section{Abstract \\ Background}

Papillary RCC (PRCC) is the second most common pathological subtype after clear cell RCC (CcRCC), representing $10-20 \%$ of treatment of renal tumors. The aim of this study was to establish a reliable nomogram model to evaluate the prognosis of papillary renal cell carcinoma (PRCC) for overall survival (OS).

\section{Patients and methods}

: In total, 6,028 patients with PRCC from the Surveillance, Epidemiology, and End Results (SEER) database were randomly separated into training $(n=4,220)$ and validation $(n=1,808)$ cohorts. Cox regression analyses were used to identify the significant variables. A nomogram was established to predict the prognosis of an individual patient with PRCC in terms of OS based on the Cox model. The predictive accuracy of the nomogram model was assessed via discrimination and calibration plots.

\section{Results}

Data of 6,028 patients with PRCC were retrieved from the SEER database. Age at diagnosis, grade, TumorNode-Metastasis stage (TNM, AJCC, 7th edition), surgical treatment, tumor number and marital status were the significant independent prognostic variables. All variables were combined to establish a nomogram. Compared to the TNM stage system 7th edition, our nomogram exhibited a favorable discrimination power for OS prediction both in the training and validation cohorts. The calibration curves revealed high consistency between the prognosis prediction of our nomogram and the actual survival.

\section{Conclusions}

The nomogram displayed a excellent performance, suggesting that it could be considered an effective and individualized tool for prognosis prediction of OS in patients with PRCC.

\section{Introduction}

Renal cell carcinoma (RCC) is a common urological malignant tumor worldwide, accounting for 62,700 new cases in the US [1] and 66,800 in China [2]. Although diagnostic techniques and targeted therapies have rapidly developed in recent years, approximately $20 \%$ of patients develop to an advanced stage by initial diagnosis, and approximately $30 \%$ of those with localized RCC, who receive curative surgery, subsequently experience recurrence $[3,4]$. Therefore, it is essential to have an accurate estimation of RCC prognosis to facilitate individualized treatment according to risk in order to select the optimal treatment strategy. 
RCC types are divided into clear cell, papillary, chromophobe and other, including less common and unclassified subtypes $[5,6]$. Papillary RCC (PRCC) is the second most common pathological subtype after clear cell RCC (ccRCC), representing 10-20\% of treatment of renal tumors [7]. In a previous study, Margulis $\vee$ et al [8] found that there were significant differences in clinical manifestations, prognostic characteristics, and patient ending between those with PRCC and ccRCC. Many previous studies have proposed methods to assist physicians in treatment decision-making for patients with RCC. The vast majority focus on $\operatorname{RCC}[9,10]$ and $\operatorname{ccRCC}[11,12]$. At present, there is a lack of agreement regarding how best to predict the survival prognosis of patients with PRCC.

Currently, the American Joint Committee on Cancer (AJCC) Staging Manual is regarded the gold standard staging scheme for predicting survival prognosis in patients with RCC [13]. In this classification system, patients are stratified on the basis of depth of invasion, number of metastasis nodes and status of distant metastasis. However, patient survival outcomes may be quite distinct even in those with the same AJCC stage. However, many other significant factors such as age, race, sex, tumor number, tumor differentiation and surgical treatment are also correlated with prognosis in multiple cancers[14, 15]. Therefore, a more refined staging system that combines clinicopathological characteristics may exhibit a more accurate and credible prediction of survival prognosis than dose the AJCC staging manual.

A nomogram, as an efficient and convenient tool for prediction, combines Tumor-Node-Metastasis (TNM) stage and other important clinicopathological characteristics to predict a specific outcome[16-19]. Combined with these clinicopathological variables, the nomogram can provide a reliable individual prediction of overall survival (OS) for patients with PRCC. Compared with the AJCC TNM staging system alone, the combination of clinicopathological variables and AJCC staging can more accurately predict the individual prognosis of OS $[20,21]$. In this study, we established a prognostic nomogram on the basis of a large amount of population information retrieved from the Surveillance, Epidemiology, and End Results (SEER) database to provide a more accurate and individualized OS prediction for patients with PRCC.

\section{Patients And Methods}

\section{Study cohort}

In the study, all clinicopathological information was collected from the SEER database via reference number 14581-Nov2017. Ethics approval was not required in present study as the data used from the SEER database are publicly available. The inclusion criteria were as follows: (1) diagnosed with PRCC; (2) with a Histologic ICD-0-3 number of 8130; (3) with complete clinicopathological characteristics including age at diagnosis, race, laterality, number of tumors, grade, surgical treatment and TNM stage (derived AJCC, $7^{\text {th }}[2010+]$ ); and (4) with detailed and available survival time and vital status. Patients without the above clinicopathological features or sufficient data were excluded from the study.

\section{Variables and endpoints}


Clinicopathological variables were: age at diagnosis, sex (female or male), race, laterality (left or right), histological grade, surgical treatment (including no surgery, partial nephrectomy, and radical nephrectomy), number of tumors (multiple or single), and $7^{\text {th }}$ AJCC tumor stage, including $\mathrm{T} 1 / \mathrm{T} 2 / \mathrm{T} 3 / \mathrm{T} 4 / \mathrm{N} 0 / \mathrm{N} 1 / \mathrm{M} 0 / \mathrm{M} 1$ stage. Both the number of tumors and age at diagnosis were converted into classification variables for subsequent analysis. The OS of patients with PRCC served as the endpoint.

\section{Nomogram validation}

The internal and external validations were conducted using training and validation cohorts, respectively. First, the concordance index (C-index), which is similar to the area under curve (AUC) of the receiver operating characteristic (ROC) cure but more suitable for censored data, was applied for the evaluation of discrimination for the nomogram[22]. The C-index was also applied to assess the performance of the $7^{\text {th }}$ AJCC system in prognostic prediction. The range of the C-index statistic was from 0.5 to 1 , and a greater C-index represented a more favorable prognostic discrimination of the model. Next, calibration cures of the nomogram were applied to assess the consistency between prediction and observation of OS. To decrease the overfit bias, bootstrap was corrected, evaluating with 1,000 resamples[20].

\section{Statistical analyses}

The independent prognostic variables correlated to OS were screened out via univariate and multivariate Cox regression analyses. Then, the risk score (RS) of the multiple Cox regression model was estimated using the following formula:

$$
\mathrm{RS}=\sum_{i=1}^{n} \operatorname{Exp}(i) R(i)
$$

where $n$ represents the the number of clinicopathological variables; $\operatorname{Exp}(i)$ represents the value of each variable; and $R(i)$ represents the regression coefficient of each variable. The sample with an RS less than the average RS of all samples was considered a low-risk sample; otherwise, the sample was considered high-risk. Survival curves for high- and low-risk groups were plotted using the Kaplan-Meier method. In addition, the specificity and sensitivity were estimated by ROC curve and areas under the ROC curve (AUC value).

In this study, differences were regarded as significant at $p$-value $<0.05$. Statistical tests were conducted using the R software.

\section{Results}

\section{Patient characteristics}


Overall, 6,028 eligible patients with PRCC were selected and composed the primary cohort. Of these, 4,220 were randomly assigned into a training cohort for construction and internal validation of our nomogram, while 1,808 patients made up the validation cohort for external validation. The clinicopathologic and demographic features of these cohorts are presented in Table 1. At the end of the follow-up period, 485 cases in the training and 210 in the validation cohorts had died. The average OS for both cohorts was 31 months. In the training and validation cohorts, most cases were male, older than 50 years, white with $\mathrm{T} 1$, N0, and M0 stages, and approximately two-thirds cases had a single tumor. Notably, the incidence of the original PRCC occurring on the left was similar to that on the right. Moreover, most patients with PRCC received a nephrectomy including partial and radical nephrectomy. 
Table 1

Patient demographics and clinical characteristics

\begin{tabular}{|c|c|c|c|c|c|c|}
\hline Variables & $\begin{array}{l}\text { primary } \\
\text { cohort }(n= \\
6028)\end{array}$ & $\begin{array}{l}\text { primary } \\
\text { cohort } \\
(\%)\end{array}$ & $\begin{array}{l}\text { Training } \\
\text { cohort ( } \mathrm{n}= \\
4220)\end{array}$ & $\begin{array}{l}\text { Training } \\
\text { cohort } \\
(\%)\end{array}$ & $\begin{array}{l}\text { Validation } \\
\text { cohort }(\mathrm{n}= \\
1808)\end{array}$ & $\begin{array}{l}\text { Validation } \\
\text { cohort (\%) }\end{array}$ \\
\hline \multicolumn{7}{|l|}{$\begin{array}{l}\text { Age at } \\
\text { diagnosis } \\
\text { (years) }\end{array}$} \\
\hline$<40$ & 218 & $3.62 \%$ & 150 & $3.55 \%$ & 68 & $3.76 \%$ \\
\hline $40-49$ & 609 & $10.10 \%$ & 420 & $9.95 \%$ & 189 & $10.45 \%$ \\
\hline $50-59$ & 1508 & $25.02 \%$ & 1043 & $24.72 \%$ & 465 & $25.72 \%$ \\
\hline $60-69$ & 2096 & $34.77 \%$ & 1482 & $35.12 \%$ & 614 & $33.96 \%$ \\
\hline 70-79 & 1262 & $20.94 \%$ & 881 & $20.88 \%$ & 381 & $21.07 \%$ \\
\hline$>=80$ & 335 & $5.56 \%$ & 244 & $5.78 \%$ & 91 & $5.03 \%$ \\
\hline \multicolumn{7}{|l|}{ Sex } \\
\hline Male & 4559 & $75.63 \%$ & 3187 & $75.52 \%$ & 1372 & $75.88 \%$ \\
\hline Female & 1469 & $24.37 \%$ & 1033 & $24.48 \%$ & 436 & $24.12 \%$ \\
\hline \multicolumn{7}{|l|}{ Race } \\
\hline Black & 1793 & $29.74 \%$ & 1251 & $29.64 \%$ & 542 & $29.98 \%$ \\
\hline White & 4008 & $66.49 \%$ & 2813 & $66.66 \%$ & 1195 & $66.10 \%$ \\
\hline Other & 227 & $3.77 \%$ & 156 & $3.70 \%$ & 71 & $3.93 \%$ \\
\hline \multicolumn{7}{|l|}{ Laterality } \\
\hline Left & 3026 & $50.20 \%$ & 2124 & $50.33 \%$ & 902 & $49.89 \%$ \\
\hline Right & 3002 & $49.80 \%$ & 2096 & $49.67 \%$ & 906 & $50.11 \%$ \\
\hline \multicolumn{7}{|l|}{ Grade } \\
\hline I & 654 & $10.85 \%$ & 468 & $11.09 \%$ & 186 & $10.29 \%$ \\
\hline II & 3122 & $51.79 \%$ & 2150 & $50.95 \%$ & 972 & $53.76 \%$ \\
\hline III & 2059 & $34.16 \%$ & 1464 & $34.69 \%$ & 595 & $32.91 \%$ \\
\hline IV & 193 & $3.20 \%$ & 138 & $3.27 \%$ & 55 & $3.04 \%$ \\
\hline \multicolumn{7}{|l|}{ T stage } \\
\hline T1 & 4683 & $77.69 \%$ & 3278 & $77.68 \%$ & 1405 & $77.71 \%$ \\
\hline T2 & 646 & $10.72 \%$ & 448 & $10.62 \%$ & 198 & $10.95 \%$ \\
\hline
\end{tabular}




\begin{tabular}{|c|c|c|c|c|c|c|}
\hline Variables & $\begin{array}{l}\text { primary } \\
\text { cohort }(n= \\
6028)\end{array}$ & $\begin{array}{l}\text { primary } \\
\text { cohort } \\
(\%)\end{array}$ & $\begin{array}{l}\text { Training } \\
\text { cohort ( } \mathrm{n}= \\
4220)\end{array}$ & $\begin{array}{l}\text { Training } \\
\text { cohort } \\
\text { (\%) }\end{array}$ & $\begin{array}{l}\text { Validation } \\
\text { cohort }(n= \\
1808)\end{array}$ & $\begin{array}{l}\text { Validation } \\
\text { cohort (\%) }\end{array}$ \\
\hline T3 & 658 & $10.92 \%$ & 465 & $11.02 \%$ & 193 & $10.67 \%$ \\
\hline T4 & 41 & $0.68 \%$ & 29 & $0.69 \%$ & 12 & $0.66 \%$ \\
\hline \multicolumn{7}{|l|}{$\mathrm{N}$ stage } \\
\hline NO & 5799 & $96.20 \%$ & 4057 & $96.14 \%$ & 1742 & $96.35 \%$ \\
\hline N1 & 229 & $3.80 \%$ & 163 & $3.86 \%$ & 66 & $3.65 \%$ \\
\hline \multicolumn{7}{|l|}{ M stage } \\
\hline MO & 5860 & $97.21 \%$ & 4100 & $97.16 \%$ & 1760 & $97.35 \%$ \\
\hline M1 & 168 & $2.79 \%$ & 120 & $2.84 \%$ & 48 & $2.65 \%$ \\
\hline \multicolumn{7}{|l|}{$\begin{array}{l}\text { Surgical } \\
\text { treatment }\end{array}$} \\
\hline No surgery & 153 & $2.54 \%$ & 105 & $2.49 \%$ & 48 & $2.65 \%$ \\
\hline $\begin{array}{l}\text { Partial } \\
\text { nephrectomy }\end{array}$ & 3335 & $55.33 \%$ & 2341 & $55.47 \%$ & 994 & $54.98 \%$ \\
\hline $\begin{array}{l}\text { Radical } \\
\text { nephrectomy }\end{array}$ & 2540 & $42.14 \%$ & 1774 & $42.04 \%$ & 766 & $42.37 \%$ \\
\hline \multicolumn{7}{|l|}{$\begin{array}{l}\text { Tumor } \\
\text { number }\end{array}$} \\
\hline Solitary & 3976 & $65.96 \%$ & 2771 & $65.66 \%$ & 1205 & $66.65 \%$ \\
\hline multiple & 2052 & $34.04 \%$ & 1449 & $34.34 \%$ & 603 & $33.35 \%$ \\
\hline \multicolumn{7}{|l|}{$\begin{array}{l}\text { Marital } \\
\text { status }\end{array}$} \\
\hline Married & 3584 & $59.46 \%$ & 2500 & $59.24 \%$ & 1084 & $59.96 \%$ \\
\hline Unmarried & 2102 & $34.87 \%$ & 1484 & $35.17 \%$ & 618 & $34.18 \%$ \\
\hline unknown & 342 & $5.67 \%$ & 236 & $5.59 \%$ & 106 & $5.86 \%$ \\
\hline
\end{tabular}

\section{Independent Prognostic Variables Of The Training Cohort}

The effects of all variables on OS were analyzed using the univariate and multivariate Cox regression analyses, and the impact of each variable on OS was quantified using the hazard ratio. The following variables were included in the analyses above: age at diagnosis, sex, race, laterality, Fuhrman grade, TNM stage (TNM, AJCC, 7th edition), surgical treatment, number of tumors, and marital status. The results are 
revealed in Table 2. All variables except sex, race, and laterality showed statistical significance, both in univariate and multivariable Cox regression analyses 
Table 2

Univariate and multivariate Cox regression model analyses of overall survival in nomogram cohort

\section{Variables}

Multivariable cox

Overall survival

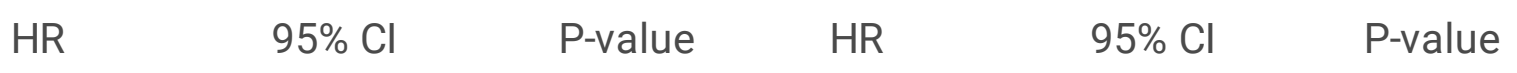

Age at diagnosis (years)

\begin{tabular}{|c|c|c|c|c|c|c|}
\hline$<40$ & 1 (refere & & & 1 (referenc & & \\
\hline $40-49$ & 1.1338 & $\begin{array}{l}0.4843- \\
2.654\end{array}$ & 0.772381 & 1.503870 & $\begin{array}{l}0.6372- \\
3.5492\end{array}$ & $\begin{array}{l}3.5166 \mathrm{E}- \\
01\end{array}$ \\
\hline $50-59$ & 1.9843 & $\begin{array}{l}0.9206- \\
4.277\end{array}$ & 0.080301 & 2.976736 & $\begin{array}{l}1.3706- \\
6.4649\end{array}$ & $\begin{array}{l}5.8400 \mathrm{E}- \\
03\end{array}$ \\
\hline $60-69$ & 2.2361 & $\begin{array}{l}1.0474- \\
4.774\end{array}$ & 0.037552 & 3.567077 & $\begin{array}{l}1.6543- \\
7.6916\end{array}$ & $\begin{array}{l}1.1800 \mathrm{E}- \\
03\end{array}$ \\
\hline $70-79$ & 4.0414 & $\begin{array}{l}1.8937- \\
8.625\end{array}$ & 0.000305 & 5.534472 & $\begin{array}{l}2.5692- \\
11.9220\end{array}$ & $\begin{array}{l}1.2400 \mathrm{E}- \\
05\end{array}$ \\
\hline$>=80$ & 6.9905 & $\begin{array}{l}3.2088- \\
15.229\end{array}$ & $\begin{array}{l}9.850000 \mathrm{E}- \\
07\end{array}$ & 7.214497 & $\begin{array}{l}3.2791- \\
15.8730\end{array}$ & $\begin{array}{l}9.0300 \mathrm{E}- \\
07\end{array}$ \\
\hline
\end{tabular}

Sex

Female

1

(reference)

1

(reference)

Male

1.1611

0.9354-

1.441

0.176000

1.233124

0.9814-

1.5495

$7.2110 \mathrm{E}-$ 02

Race

Black

1 (reference)

(reference)

White

1.1566

0.9448-

1.416

0.159000

1.091214

0.8828-

1.3488

4.1949E-

01

Other

1.03117

0.6220-

1.710

0.905000

1.006067

$0.6016-$

1.6823

$9.8160 \mathrm{E}-$ 01

Laterality

Left

${ }^{1}$ (reference)

1

(reference)

Right

$\begin{array}{ll}0.94464 & 0.7906- \\ & 1.129\end{array}$

0.531000

0.976762

0.8161-

7.9756E-

Grade 


\begin{tabular}{|c|c|c|c|c|c|c|}
\hline Variables & \multicolumn{3}{|c|}{ Univariable cox } & \multicolumn{3}{|c|}{ Multivariable cox } \\
\hline I & $\begin{array}{l}1 \\
\text { (reference) }\end{array}$ & & & $\begin{array}{l}1 \\
\text { (reference) }\end{array}$ & & \\
\hline II & 1.05116 & $\begin{array}{l}0.7532- \\
1.467\end{array}$ & 0.769240 & 0.999093 & $\begin{array}{l}0.7133- \\
1.3994\end{array}$ & $\begin{array}{l}9.9579 \mathrm{E}- \\
01\end{array}$ \\
\hline III & 1.7657 & $\begin{array}{l}1.2660- \\
2.463\end{array}$ & 0.000810 & 1.313180 & $\begin{array}{l}0.9310- \\
1.8523\end{array}$ & $\begin{array}{l}1.2056 \mathrm{E}- \\
01\end{array}$ \\
\hline IV & 4.82287 & $\begin{array}{l}3.1730- \\
7.331\end{array}$ & $\begin{array}{l}1.770000 \mathrm{E}- \\
13\end{array}$ & 1.604468 & $\begin{array}{l}1.0272- \\
2.5061\end{array}$ & $\begin{array}{l}3.7720 \mathrm{E}- \\
02\end{array}$ \\
\hline \multicolumn{7}{|l|}{ T stage } \\
\hline T1 & $\begin{array}{l}1 \\
\text { (reference) }\end{array}$ & & & $\begin{array}{l}1 \\
\text { (reference) }\end{array}$ & & \\
\hline T2 & 2.0096 & $\begin{array}{l}1.547- \\
2.611\end{array}$ & $\begin{array}{l}1.710000 \mathrm{E}- \\
07\end{array}$ & 1.297429 & $\begin{array}{l}0.9855- \\
1.7081\end{array}$ & $\begin{array}{l}6.3480 \mathrm{E}- \\
02\end{array}$ \\
\hline T3 & 3.7183 & $\begin{array}{l}3.008- \\
4.596\end{array}$ & $<2 \mathrm{e}-16$ & 1.795167 & $\begin{array}{l}1.3966- \\
2.3075\end{array}$ & $\begin{array}{l}4.9200 \mathrm{E}- \\
06\end{array}$ \\
\hline T4 & 12.732 & $\begin{array}{l}8.074- \\
20.079\end{array}$ & $<2 \mathrm{e}-16$ & 1.855480 & $\begin{array}{l}1.0995- \\
3.1311\end{array}$ & $\begin{array}{l}2.0590 \mathrm{E}- \\
02\end{array}$ \\
\hline \multicolumn{7}{|l|}{$\mathrm{N}$ stage } \\
\hline NO & $\begin{array}{l}1 \\
\text { (reference) }\end{array}$ & & & $\begin{array}{l}1 \\
\text { (reference) }\end{array}$ & & \\
\hline N1 & 10.1229 & $8.03-12.76$ & $<2 \mathrm{e}-16$ & 2.424620 & $\begin{array}{l}1.7871- \\
3.2896\end{array}$ & $\begin{array}{l}1.2700 \mathrm{E}- \\
08\end{array}$ \\
\hline \multicolumn{7}{|l|}{ M stage } \\
\hline MO & $\begin{array}{l}1 \\
\text { (reference) }\end{array}$ & & & & $\begin{array}{l}1 \\
\text { (reference) }\end{array}$ & \\
\hline M1 & 14.3808 & $11.3-18.3$ & $<2 \mathrm{e}-16$ & 5.148121 & $\begin{array}{l}3.7649- \\
7.0396\end{array}$ & $<2 \mathrm{e}-16$ \\
\hline \multicolumn{7}{|l|}{$\begin{array}{l}\text { Surgical } \\
\text { treament }\end{array}$} \\
\hline No surgery & $\begin{array}{l}1 \\
\text { (reference) }\end{array}$ & & & $\begin{array}{l}1 \\
\text { (reference) }\end{array}$ & & \\
\hline $\begin{array}{l}\text { Partial } \\
\text { nephrectomy }\end{array}$ & 0.07895 & $\begin{array}{l}0.05599- \\
0.1113\end{array}$ & $<2 \mathrm{e}-16$ & 0.147048 & $\begin{array}{l}0.1019- \\
0.2122\end{array}$ & $<2 \mathrm{e}-16$ \\
\hline $\begin{array}{l}\text { Radical } \\
\text { nephrectomy }\end{array}$ & 0.29335 & $\begin{array}{l}0.21460- \\
0.4010\end{array}$ & $\begin{array}{l}1.480000 \mathrm{E}- \\
14\end{array}$ & 0.375394 & $\begin{array}{l}0.2679- \\
0.5260\end{array}$ & $\begin{array}{l}1.2600 \mathrm{E}- \\
08\end{array}$ \\
\hline
\end{tabular}




\begin{tabular}{|c|c|c|c|c|c|c|}
\hline Variables & \multicolumn{3}{|c|}{ Univariable cox } & \multicolumn{3}{|c|}{ Multivariable cox } \\
\hline Solitary & $\begin{array}{l}1 \\
\text { (reference }\end{array}$ & & & $\begin{array}{l}1 \\
\text { (reference) }\end{array}$ & & \\
\hline Multiple & 1.36058 & $\begin{array}{l}1.136- \\
1.629\end{array}$ & 0.000798 & 1.313865 & $\begin{array}{l}1.0902- \\
1.5835\end{array}$ & $\begin{array}{l}4.1500 \mathrm{E}- \\
03\end{array}$ \\
\hline \multicolumn{7}{|c|}{ Marital status } \\
\hline Married & $\begin{array}{l}1 \\
\text { (reference }\end{array}$ & & & $\begin{array}{l}1 \\
\text { (reference) }\end{array}$ & & \\
\hline Unmarried & 1.39318 & $\begin{array}{l}1.1577- \\
1.677\end{array}$ & 0.000448 & 1.349821 & $\begin{array}{l}1.1065- \\
1.6466\end{array}$ & $\begin{array}{l}3.0900 \mathrm{E}- \\
03\end{array}$ \\
\hline Unknown & 1.22034 & $\begin{array}{l}0.8359- \\
1.782\end{array}$ & 0.302263 & 1.382200 & $\begin{array}{l}0.9381- \\
2.0365\end{array}$ & $\begin{array}{l}1.0163 \mathrm{E}- \\
01\end{array}$ \\
\hline
\end{tabular}

Based on the RS, patients in the training cohort were divided into a low- and high-risk group. The results of survival analysis showed those patients in the low-risk group had dramatically longer survival time than that in the high-risk group (Fig. 1). Then, time-dependent ROC curve analysis was adopted, and AUC values were used to test the sensitivity and specificity of the survival prediction. The results suggested that AUC values for three- and five-year survival prediction were 0.777 and 0.757 , respectively (Fig. 2), indicating high prediction performances.

According to Table 2, survival curves for these variables were plotted using Kaplan-Meier method and are presented in Figs. 3 and 4. The results indicated that age at diagnosis, Fuhrman grade, TNM stage, surgical treatment, tumor number and marital status were the independent risk factors for OS in patients with PRCC (Fig. 3). However, sex, race and laterality had no significantly association with OS (Fig. 4).

\section{Prognostic Nomogram For Os}

The variables mentioned above were employed in the nomogram for OS prediction at three- and five-years in patients with PRCC(Fig. 5). The nomogram assigned a score for each subtype of the variables. By adding up the scores associated with each variable, thus locating the total score on the bottom scales, OS predictions at three- and five-years were performed. The nomogram suggested that being aged over 80 years was the main contributor to OS, followed by surgical treatment and AJCC TNM stage. Laterality and race showed a minimal effect on OS.

For example, a 70-year-old black, male, married patient with a tumor originally located on the right that was grade IV and, T2NOM0 stage would receive a radical nephrectomy score $>180$, indicating that the probabilities of survival at three- and five-years are approximately $75 \%$ and $60 \%$, respectively.

\section{Validation Of The Nomogram}


C-indexes for our nomogram were $0.807(95 \% \mathrm{Cl}, 0.779$ to 0.834$)$ and $0.800(95 \% \mathrm{Cl}, 0.759$ to 0.841$)$ in training and validation cohorts, indicating the applicability and feasibility of the established nomogram for patients with PRCC. Moreover, the differences between our nomogram and the AJCC TNM staging system 7th edition in the prediction of OS were compared using the training and validation cohorts. Cindexes for AJCC TNM staging were $0.686(95 \% \mathrm{Cl}, 0.667$ to 0.706$)$ and $0.668(95 \% \mathrm{Cl}, 0.638$ to 0.697$)$ in training and validation cohorts, respectively, which are dramatically smaller than those of the nomogram. This suggests that our nomogram discrimination is superior to the AJCC TNM staging in the prediction of OS. Additionally, both internal and external calibration diagrams for three- and five-years OS indicate good correlation and high reliability for the training and validation cohorts between the nomogram predictions and observations (Figs. 6 and 7).

\section{Discussion}

To date, numerous prediction models have been developed to evaluate survival outcomes in patients with PRCC, using different variables. In 2007, Karakjewicz et at [23] constructed a postoperative renal cancerspecific survival nomogram based on 2530 patients receiving either radical or partial nephrectomy and the nomogram was validated using a cohort of 1,422 external cases. The factors included in this nomogram were the 2002 TNM staging system, tumor size, histologic subtype, Fuhrman grade, local symptoms, age and gender. The predictive precision for one, two, five and 10 years after nephrectomy was $87.8 \%, 89.2 \%, 86.7 \%$ and $88.6 \%$, respectively. The UISS [24] and the Cindolo model [25] also used widely to predict survival outcomes of patients with PRCC after nephrectomy. Recently, Zhang et al [12] found that age at diagnosis, race, sex, Fuhrman grade, marital status, TNM stage and surgical approach were markedly associated with the prognosis of patients with ccRCC, and they developed nomograms based on the factors mentioned above to predict three-, five- and 10-year overall and disease-specific survival. To our knowledge, a disease-specific survival nomogram for patients with PRCC was constructed by Klatte et al for the first time [26]. In their study, T classification, M classification,incidental detection, extent of tumor necrosis, and vascular invasion were considered independent prognostic factors, which were combined to develop the nomogram. However, this nomogram relied on a small patient cohort (258 for development and 177 for external validation), which undermined the power of their outcomes.

In our study, a nomogram was established for individual OS prediction according to a large population of patients with PRCC from the SEER database for the first time. Our nomogram combined individual clinicopathological and demographic information and exhibited excellent discrimination in either internal or external validation, showing suitable clinical practicality and appropriateness for patients with PRCC. Moreover, the nomogram revealed more favorable precision and reliability than the AJCC TNM staging system 7th edition in terms of OS prediction. Additionally, survival curves of each independent prognostic variable were estimated using the Kaplan-Meier method, suggesting a significant correlation between all variables and OS. 
Our nomogram consisted of nine variables, including age at diagnosis, sex, race, laterality, Fuhrman grade, number of tumors, TNM stage, surgical treatment and marital status. Age was considered a significant prognostic variable for OS in previous studies [27, 28], as it could be related to the decline of human organs with the increase of age. Our results from the Kaplan-Meier curve analysis revealed that as age increas, the OS of patients with PRCC decreases, and patients older than 80 years have the shortest survival time. Patients who had a higher TNM stage and Fuhrman grade were correlated with an unfavorable prognosis. Furthermore, patients undergoing partial nephrectomy appeared to have greater OS than those who underwent radical nephrectomy or no surgery. This could be because most patients undergoing partial nephrectomy were at an earlier TNM stage. Based on the survival curves, we noticed that patients with a single tumor tended to have a better prognosis than those with multiple tumors. Notably, our results showed that race, sex, and laterality had no significant correlation with the OS of patients with PRCC, which was in accordance with the results of multivariate Cox regression analysis.

Lam et al [29] reported that the TNM stage alone is not sufficient to effectively predict the prognosis because of survival heterogeneity even in individual stages. Compared with TNM staging, our nomogram model is not only simple, but can also provide a quantitative and reliable tool for the prognostic prediction of an individual patient with PRCC. For example, consider two PRCC cases (tumor on the right: T3N1M0: grade IV): case A) a 40-year-old black, married, female patient with a single tumor who underwent a radical nephrectomy would score approximately 170 and case B) a 50-year-old black, married, male patient with a single tumor who underwent radical nephrectomy would score approximately 215 points. According to our nomogram, the three- and five-year OS probabilities for these two patients were $80 \%, 65 \%$ and less than $65 \%$, and $45 \%$, respectively. In contrast, both cases would be considered to be the same traditional TNM stage, indicating similar prognoses. This illustrates the disadvantages of the TNM staging system in individual prognostic prediction. Therefore, our nomogram is important for the evaluation of patients with PRCC in the follow-up period and for the selection of clinical treatments. For example, younger cases with earlier TNM stages and well-differentiated histology could receive surgery due to a favorable prognosis, while older patients with a later TNM stage and poorly-differentiated histology who have short life expectancy could not undergo surgery. However, it may be ineffevtive to purely rely on TNM staging to select a therapeutic strategy for patients, and clinicians must rely on their clinical experience to make a more appropriate decision. Therefore, physicians would be better able to select the optimal therapeutic strategy for patients with PRCC using our nomogram consisting of clinicopathological variables.

Overall, our nomogram has some strengths over previous models. First, to date, this is the first study, to our knowledge, to predict OS for patients with PRCC based on a large population cohort. Second, this study included several important clinical variables, such as age at diagnosis, race, laterality, Fuhrman grade, tumor numbers, TNM stage, and marital status, which were able to improve the prognostic accuracy of the nomogram model. Third, both C-indexes and calibration plots were applied to assess the predictive accuracy of the nomogram. All C-indexes of the nomogram were over 0.7, suggesting good accuracy for OS prediction. Forth, the Kaplan-Meier curve analysis was used in this study and the results showed these variables significantly associated with OS. Finally, the clinicopathological variables in this 
model were easily available and could better reflect the patient status and tumor features, thereby providing clinicalinformation regarding PRCC.

Despite our nomogram exhibiting excellent accuracy, several limitations must be considered. First, this study was restricted by the SEER database, including in lacking a sufficient amount of data on other pivotal prognostic variables, such as the ECOG prognostic scores, detailed histological information and mode of presentation, which have proven to be predictors of survival[30], and these predictors have not yet been analyzed in this study. In addition, chemotherapy and radiotherapy data were also unavailable. Moreover, the nomogram was based on retrospective data, which inevitably results in a risk of selection bias. This model should be further verified via prospective studies. Finally, as a convenient tool for clinicians to select individualized treatment strategies, this model does not include all prognostic factors and does not provide the most precise prognostic prediction in clinical work.

\section{Conclusion}

The present study demonstrated that age at diagnosis, Fuhrman grade, TNM stage (T/N/M, AJCC, 7th edition), surgical treatment, number of tumors and marital status were independent prognostic variables in patients with PRCC. The nomogram was established to accurately predict OS in the third- and fifthyear for patients with PRCC, according to patient-specific features. The C-index showed good performance in both internal and external validations. The nomogram may be benefit for clinicians to estimate individualized prognostic prediction and provide appropriate therapeutic strategies for patients with PRCC.

\section{Abbreviations}

RCC: Renal cell carcinoma; PRCC:Papillary renal cell carcinoma; ccRCC:Clear cell renal carcinoma; AJCC:American Joint Committee on Cancer; TNM:Tumor-Node-Metastasis; OS:Overall survival; Cindex:Concordance index. SEER:Surveillance, Epidemiology, and End Results.

\section{Declarations}

\section{Acknowledgments}

The authors would like to than SEER program for providing open access to the database.

\section{Data access}

We obtained permission to access SEER database with the reference number 14581-Nov2017. Extraction of data from the SEER database does not require informed consent.

\section{Funding}

No funding. 


\section{Conflict of Interest}

Jiawu Wang declares that he has no conflict of interest. Chengyao Zhang declares that she has no conflict of interest. Yanjun Lin declares that he has no conflict of interest. Qing Jiang declare that I have no conflict of interest.

\section{Ethical approval}

All procedures performed in studies involving human participants were in accordance with the ethical standards of the institutional and/or national research committee and with the 1964 Helsinki declaration and its later amendments or comparable ethical standards.

\section{References}

1. Siegel RL, Miller KD, Jemal A. Cancer statistics, 2016, CA: a cancer journal for clinicians, 66 (2016) 7-30.

2. Chen W, Zheng R, Baade PD, Zhang S, Zeng H, Bray F, Jemal A, Yu XQ, He J. Cancer statistics in China, 2015, CA: a cancer journal for clinicians, 66 (2016) 115-132.

3. Ljungberg B, Bensalah K, Canfield S, Dabestani S, Hofmann F, Hora M, Kuczyk MA, Lam T, Marconi L, Merseburger AS, Mulders P, Powles T, Staehler M, Volpe A, Bex A. EAU guidelines on renal cell carcinoma: 2014 update, European urology, 67 (2015) 913-924.

4. Hsieh JJ, Purdue MP, Signoretti S, Swanton C, Albiges L, Schmidinger M, Heng DY, Larkin J, Ficarra V. Renal cell carcinoma, Nature reviews. Disease primers. 2017;3:17009.

5. Kovacs G, Akhtar M, Beckwith BJ, Bugert P, Cooper CS, Delahunt B, Eble JN, Fleming S, Ljungberg B, Medeiros LJ, Moch H, Reuter VE, Ritz E, Roos G, Schmidt D, Srigley JR, Storkel S, van den Berg E, Zbar B. The Heidelberg classification of renal cell tumours. J Pathol. 1997;183:131-3.

6. Truong LD, Shen SS. Immunohistochemical diagnosis of renal neoplasms. Arch Pathol Lab Med. 2011;135:92-109.

7. Belldegrun AS, Klatte T, Shuch B, LaRochelle JC, Miller DC, Said JW, Riggs SB, Zomorodian N, Kabbinavar FF, Dekernion JB, Pantuck AJ. Cancer-specific survival outcomes among patients treated during the cytokine era of kidney cancer (1989-2005): a benchmark for emerging targeted cancer therapies. Cancer. 2008;113:2457-63.

8. Margulis V, Tamboli P, Matin SF, Swanson DA, Wood CG. Analysis of clinicopathologic predictors of oncologic outcome provides insight into the natural history of surgically managed papillary renal cell carcinoma. Cancer. 2008;112:1480-8.

9. Peng D, Zhang CJ, Tang Q, Zhang L, Yang KW, Yu XT, Gong Y, Li XS, He ZS, Zhou LQ. Prognostic significance of the combination of preoperative hemoglobin and albumin levels and lymphocyte and platelet counts (HALP) in patients with renal cell carcinoma after nephrectomy. BMC Urol. 2018;18:20. 
10. Gu L, Wang Z, Chen L, Ma X, Li H, Nie W, Peng C, Li X, Gao Y, Zhang X. A proposal of post-operative nomogram for overall survival in patients with renal cell carcinoma and venous tumor thrombus. Journal of surgical oncology. 2017;115:905-12.

11. Lee BH, Feifer A, Feuerstein MA, Benfante NE, Kou L, Yu C, Kattan MW, Russo P. Validation of a Postoperative Nomogram Predicting Recurrence in Patients with Conventional Clear Cell Renal Cell Carcinoma, European urology focus, 4 (2018) 100-105.

12. Zhang G, Wu Y, Zhang J, Fang Z, Liu Z, Xu Z, Fan Y. Nomograms for predicting long-term overall survival and disease-specific survival of patients with clear cell renal cell carcinoma. OncoTargets therapy. 2018;11:5535-44.

13. Gettman MT, Blute ML, Spotts B, Bryant SC, Zincke H. Pathologic staging of renal cell carcinoma: significance of tumor classification with the 1997 TNM staging system. Cancer. 2001;91:354-61.

14. Ouyang H, Ma W, Liu F, Yue Z, Fang M, Quan M, Pan Z. Factors influencing survival of patients with pancreatic adenocarcinoma and synchronous liver metastases receiving palliative care.

Pancreatology: official journal of the International Association of Pancreatology. 2017;17:773-81.

15. Wang XD, Qian JJ, Bai DS, Li ZN, Jiang GQ, Yao J, Marital status independently predicts pancreatic cancer survival in patients treated with surgical resection: an analysis of the SEER database, Oncotarget, 7 (2016) 24880-24887.

16. Kattan MW, Reuter V, Motzer RJ, Katz J, Russo P. A postoperative prognostic nomogram for renal cell carcinoma. The Journal of urology. 2001;166:63-7.

17. Touijer K, Scardino PT. Nomograms for staging, prognosis, and predicting treatment outcomes. Cancer. 2009;115:3107-11.

18. Cao J, Yuan P, Wang L, Wang Y, Ma H, Yuan X, Lv W, Hu J. Clinical Nomogram for Predicting Survival of Esophageal Cancer Patients after Esophagectomy. Scientific reports. 2016;6:26684.

19. Fang C, Wang W, Feng X, Sun J, Zhang Y, Zeng Y, Wang J, Chen H, Cai M, Lin J, Chen M, Chen Y, Li Y, Li S, Chen J, Zhou Z. Nomogram individually predicts the overall survival of patients with gastroenteropancreatic neuroendocrine neoplasms. British journal of cancer. 2017;117:1544-50.

20. Wang Y, Li J, Xia Y, Gong R, Wang K, Yan Z, Wan X, Liu G, Wu D, Shi L, Lau W, Wu M, Shen F. Prognostic nomogram for intrahepatic cholangiocarcinoma after partial hepatectomy. Journal of clinical oncology: official journal of the American Society of Clinical Oncology. 2013;31:1188-95.

21. Dong F, Shen Y, Gao F, Shi X, Xu T, Wang X, Zhang X, Zhong S, Zhang M, Chen S, Shen Z. Nomograms to Predict Individual Prognosis of Patients with Primary Small Cell Carcinoma of the Bladder. $J$ Cancer. 2018;9:1152-64.

22. Harrell FE Jr, Lee KL, Mark DB. Multivariable prognostic models: issues in developing models, evaluating assumptions and adequacy, and measuring and reducing errors. Statistics in medicine. 1996;15:361-87.

23. Karakiewicz PI, Briganti A, Chun FK, Trinh QD, Perrotte P, Ficarra V, Cindolo L, De la Taille A, Tostain J, Mulders PF, Salomon L, Zigeuner R, Prayer-Galetti T, Chautard D, Valeri A, Lechevallier E, Descotes JL, Lang $\mathrm{H}$, Mejean A, Patard JJ. Multi-institutional validation of a new renal cancer-specific survival 
nomogram. Journal of clinical oncology: official journal of the American Society of Clinical Oncology. 2007;25:1316-22.

24. Zisman A, Pantuck AJ, Wieder J, Chao DH, Dorey F, Said JW, deKernion JB, Figlin RA, Belldegrun AS. Risk group assessment and clinical outcome algorithm to predict the natural history of patients with surgically resected renal cell carcinoma. Journal of clinical oncology: official journal of the American Society of Clinical Oncology. 2002;20:4559-66.

25. Fortunato A, Queller DC, Strassmann JE. A linear dominance hierarchy among clones in chimeras of the social amoeba Dictyostelium discoideum. J Evol Biol. 2003;16:438-45.

26. Klatte T, Remzi M, Zigeuner RE, Mannweiler S, Said JW, Kabbinavar FF, Haitel A, Waldert M, de Martino M, Marberger M, Belldegrun AS, Pantuck AJ. Development and external validation of a nomogram predicting disease specific survival after nephrectomy for papillary renal cell carcinoma. The Journal of urology. 2010;184:53-8.

27. Skillington SA, Kallogjeri D, Lewis JS Jr, Piccirillo JF. Prognostic Importance of Comorbidity and the Association Between Comorbidity and p16 in Oropharyngeal Squamous Cell Carcinoma, JAMA otolaryngology- head \& neck surgery, 142 (2016) 568-575.

28. Shen W, Sakamoto N, Yang L. Cancer-specific mortality and competing mortality in patients with head and neck squamous cell carcinoma: a competing risk analysis. Ann Surg Oncol. 2015;22:26471.

29. Lam JS, Shvarts O, Leppert JT, Figlin RA, Belldegrun AS. Renal cell carcinoma 2005: new frontiers in staging, prognostication and targeted molecular therapy. The Journal of urology. 2005;173:1853-62.

30. Flanigan RC, Polcari AJ, Hugen CM. Prognostic variables and nomograms for renal cell carcinoma. International journal of urology: official journal of the Japanese Urological Association. 2011;18:2031.

\section{Figures}




\section{Surival curve of risk score $(P=0)$}

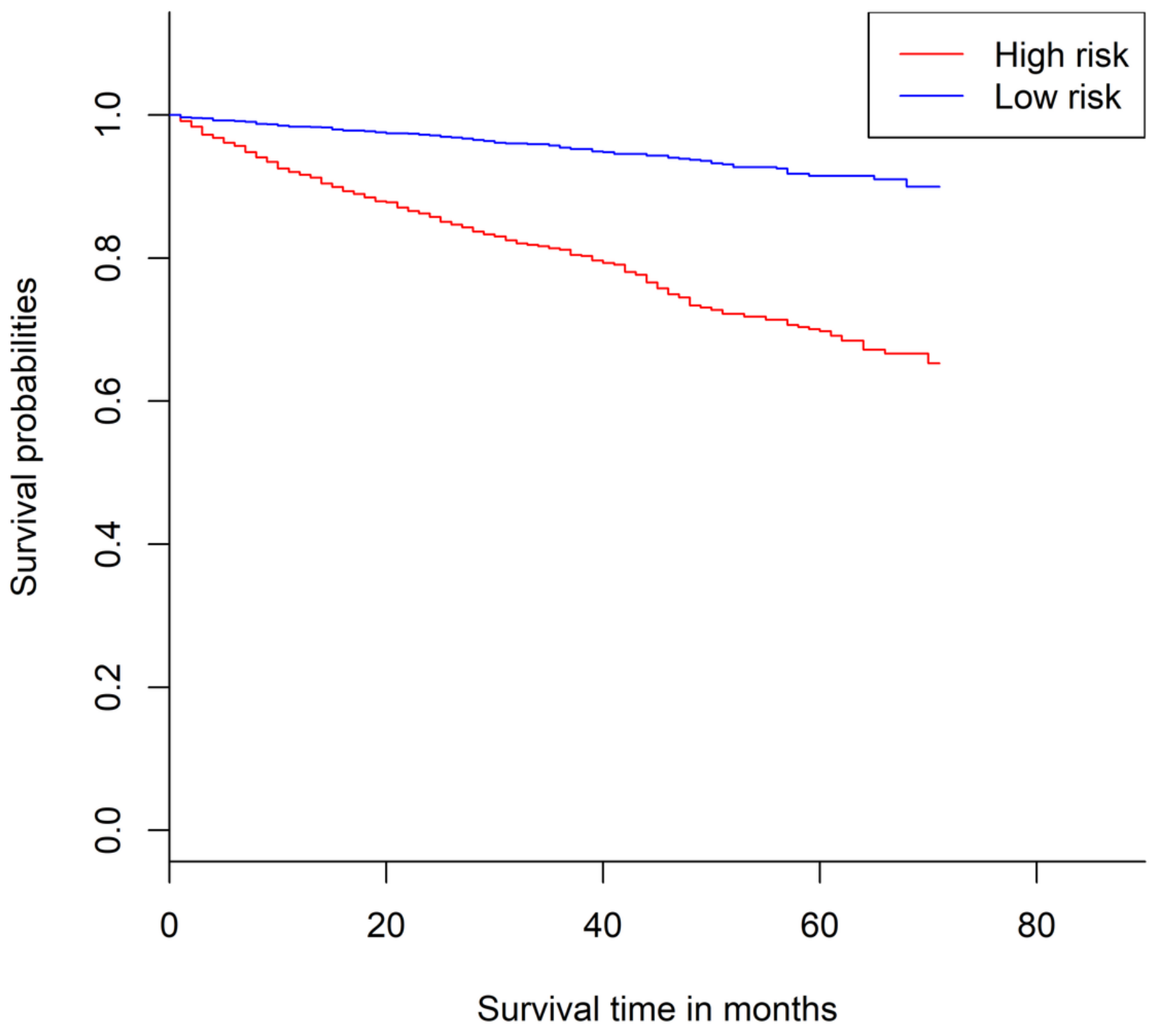

Figure 1

Kaplan-Meier survival curves for risk associated with OS in PRCC 
3-year Survival AUC $=0.777$

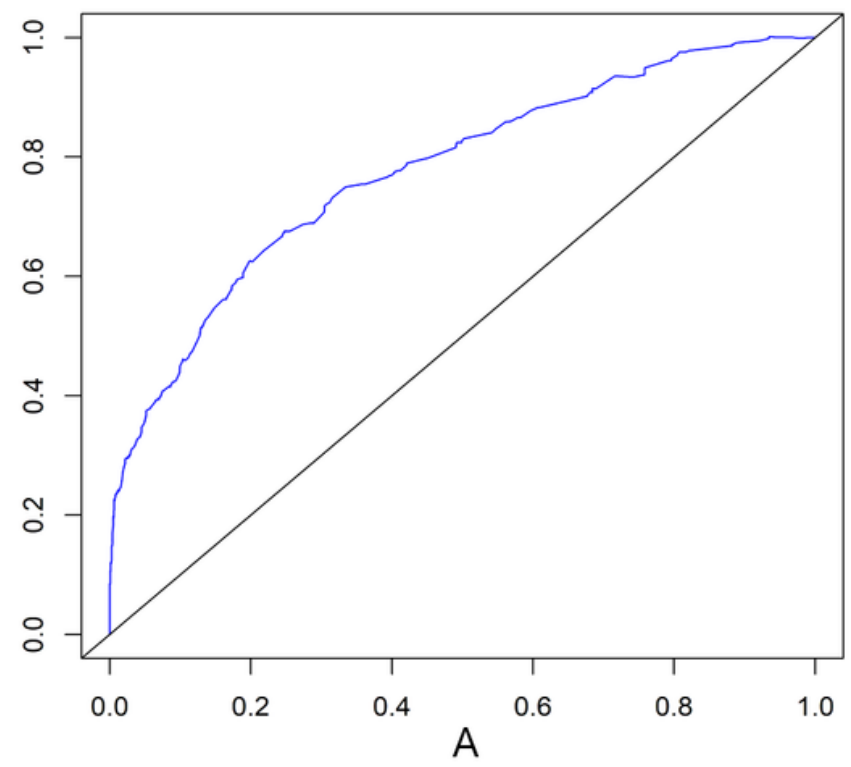

5-year Survival AUC $=0.757$

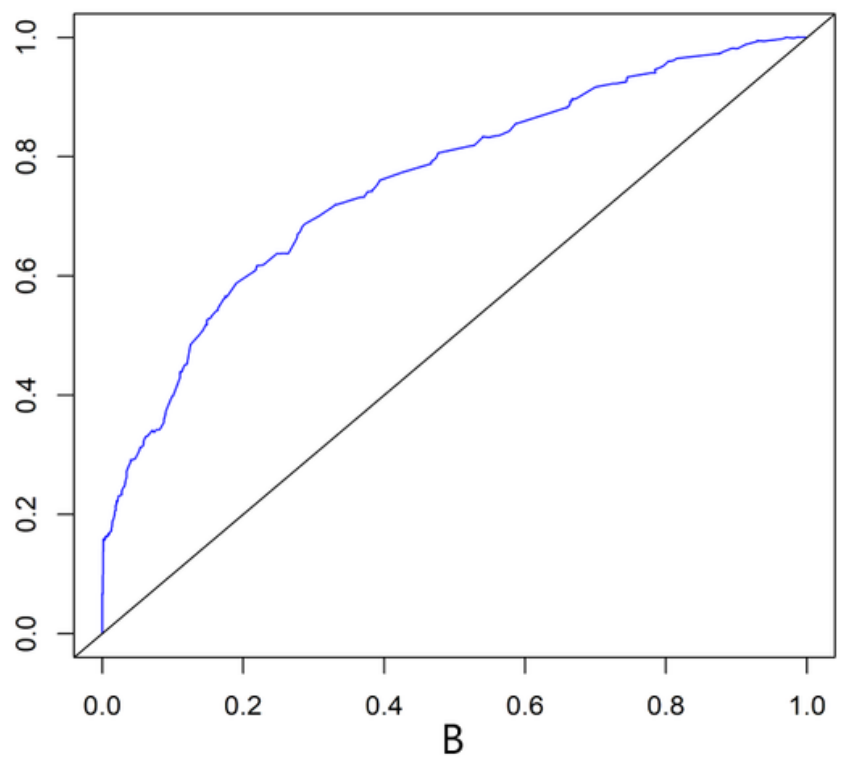

\section{Figure 2}

ROC analysis and AUC value of the ROC curve indicating the sensitivity and specificity for OS (A for 3year OS, B for 5-year OS)
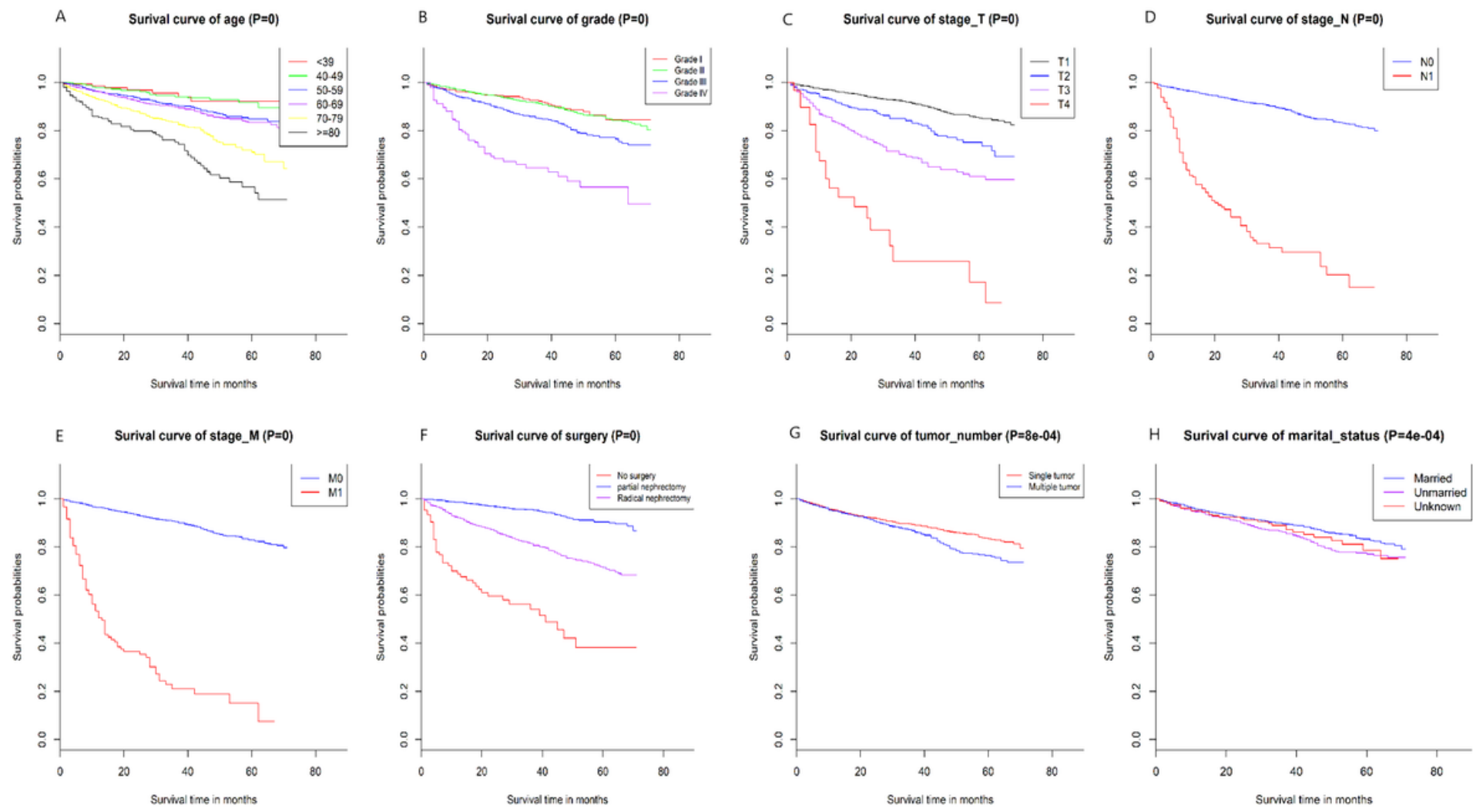

Figure 3 
Kaplan-Meier survival curves for the significant variables associated with OS in PRCC (A for age at diagnosis, $\mathrm{B}$ for Fuhrman grade, $\mathrm{C}$ for $\mathrm{T}$ stage, $\mathrm{D}$ for $\mathrm{N}$ stage, $\mathrm{E}$ for $\mathrm{M}$ stage, $\mathrm{F}$ for surgical treatment, $\mathrm{G}$ for tumor number, $\mathrm{H}$ for marital status)
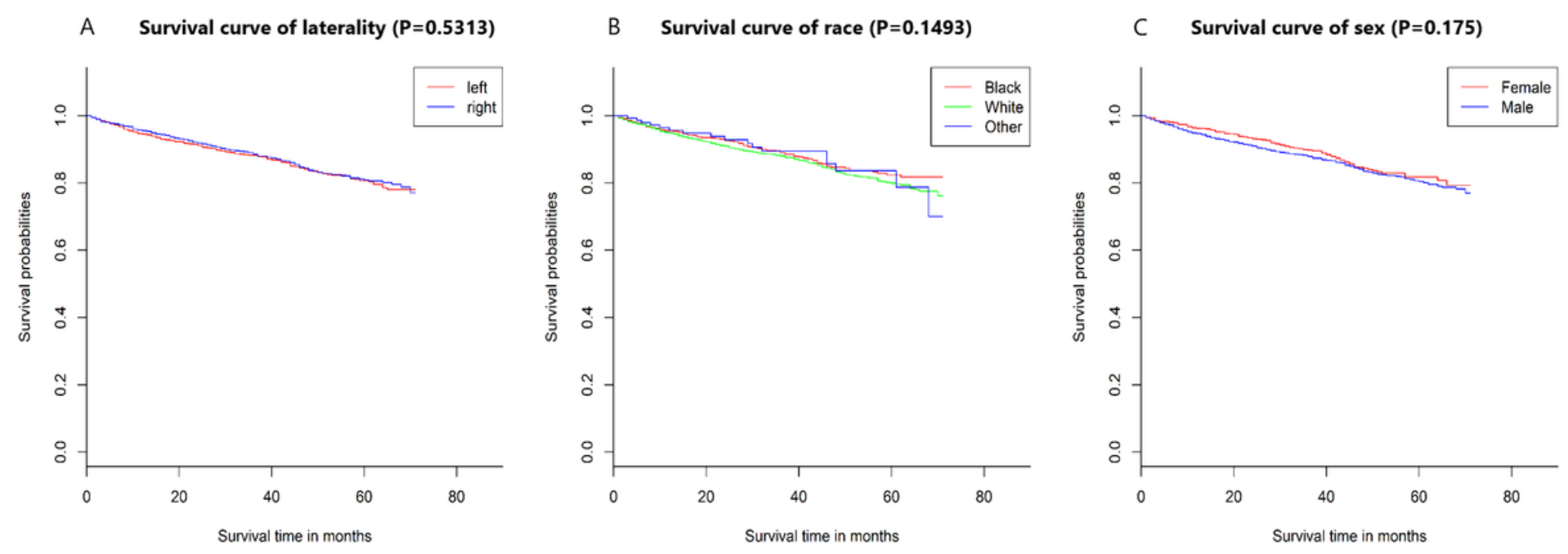

\section{Figure 4}

Kaplan-Meier survival curves for the non-significant variables associated with OS in PRCC (A for laterality, $B$ for race, $C$ for $T$ sex) 


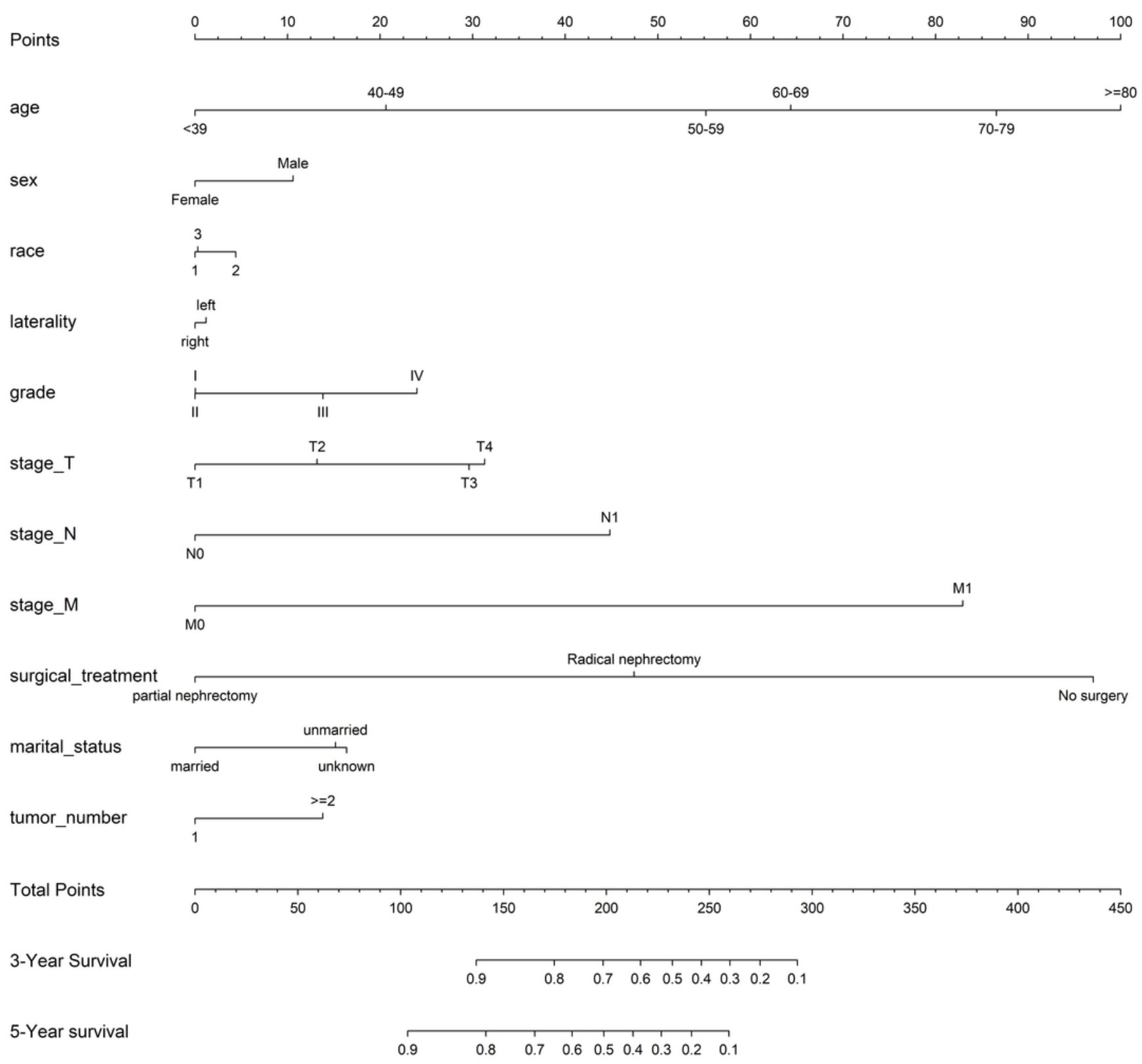

\section{Figure 5}

Nomograms for predicting the 3-and 5-year OS of PRCC patients. Race: 3 stands for black; 2 stands for white; 3 stands for American Indian/AK Native, Asian/Pacific Islander. 


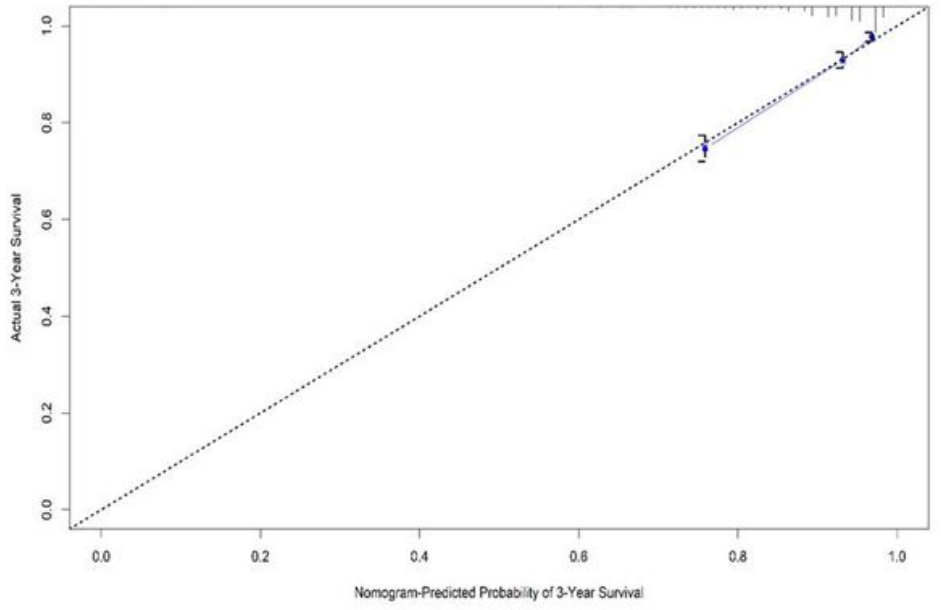

A

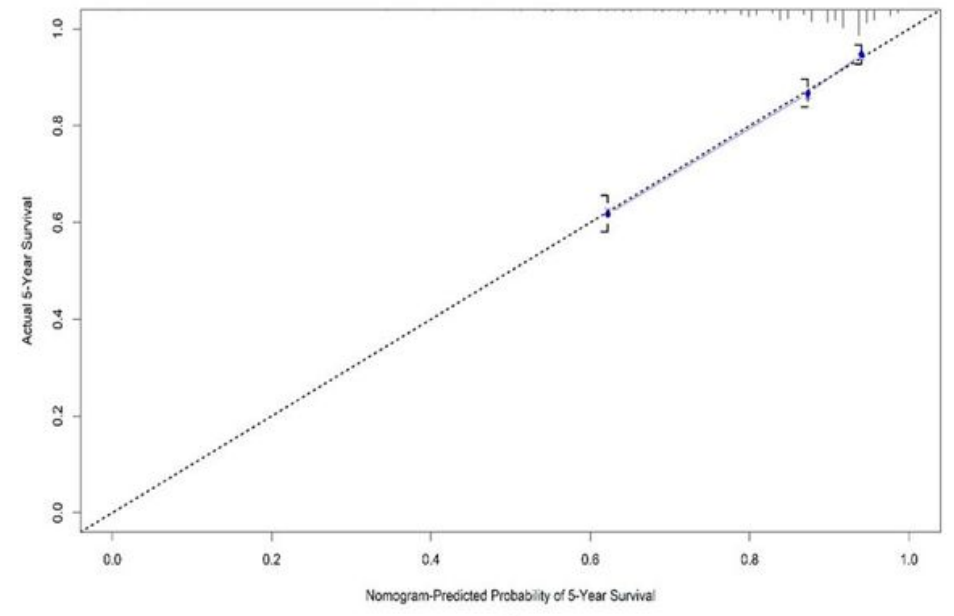

B

\section{Figure 6}

The calibration curves of 3- and 5-year OS for training cohort (A for 3-year OS, B for 5-year OS). Nomogram-predicted probability of survival is plotted on the x-axis, and the actual survival is plotted on the $y$-axis. Dashed lines through the point of origin represent the perfect calibration models where the predicted probabilities are identical to the actual probabilities. OS, overall survival

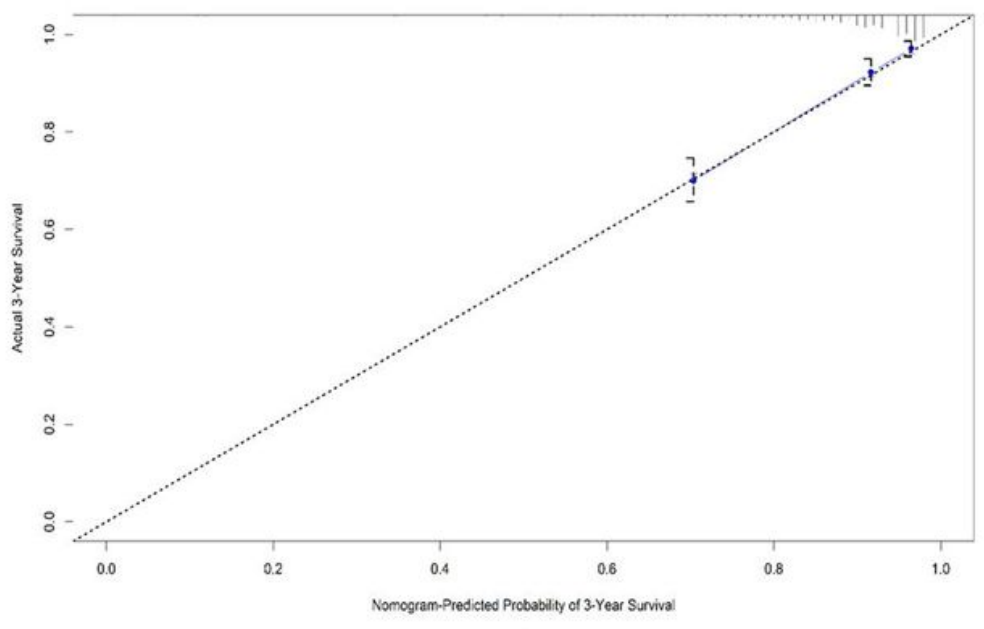

A

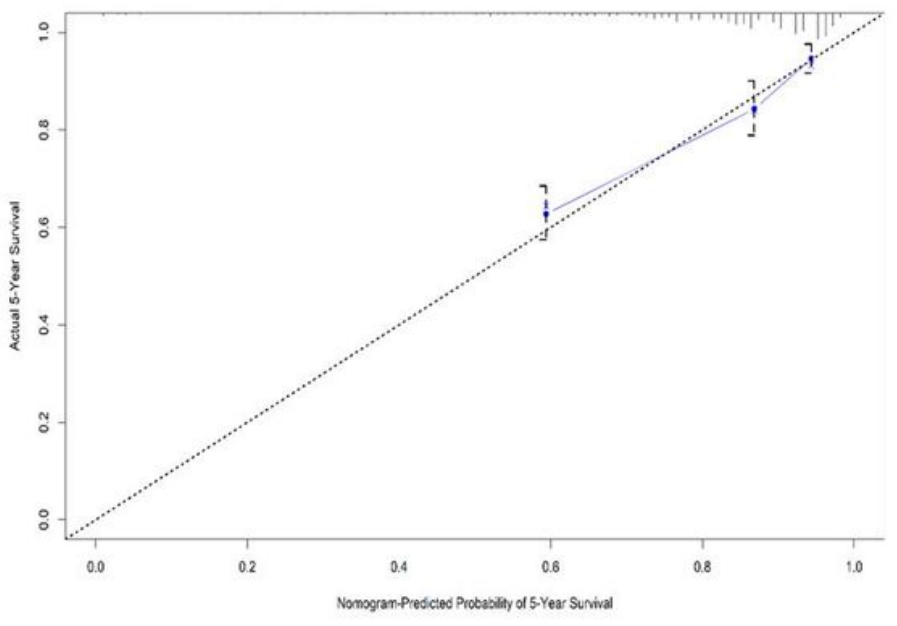

B

\section{Figure 7}

The calibration curves of 3- and 5-year OS for validation cohort (A for 3-year OS, B for 5-year OS). Nomogram-predicted probability of survival is plotted on the $x$-axis, and the actual survival is plotted on the $y$-axis. Dashed lines through the point of origin represent the perfect calibration models where the predicted probabilities are identical to the actual probabilities. OS, overall survival 